\title{
Biomass and oil content of microalgae under mixotrophic conditions
}

\author{
Hee-Jeong Choi ${ }^{\dagger}$, Seung-Mok Lee \\ Department of Environmental Engineering, Catholic Kwandong University, Gangneung 210-701, Korea
}

\begin{abstract}
The growth of the algae strains Neochloris oleabundans, Botryococcus Braunii and Dunaliella sp. under mixotrophic conditions in the presence of different concentrations of crude glycerol was evaluated with the objective of increasing the biomass growth and algal oil content. A high biomass concentration was characteristic of these strains when grown on crude glycerol compared to autotrophic growth, and $5 \mathrm{~g} / \mathrm{L}$ glycerol yielded the highest biomass concentration for these strains. Mixotrophic conditions improved both the growth of the microalgae and the accumulation of triacylglycerols (TAGs). The maximum amount of TAGs in the algal strains was obtained in the $5 \mathrm{~g} / \mathrm{L}$ glycerol growth medium. The fatty acid profiles of the oil for the cultures met the necessary requirements and are promising resources for biofuel production.
\end{abstract}

Keywords: Biomass, Glycerol, Microalgae, Mixotrophic, Oil content

\section{Introduction}

Algae cultures have primarily been developed as an important source of aquaculture feeds, human food supplements and pharmaceutical [1], and algae have been proposed as a good candidate for fuel production [2]. Algae strains that are robust and highly productive are selected for the conversion of biomass into energy [3], and strains with relatively high lipid contents are highly attractive for biodiesel fuel production [4]. Microalgae have high growth rates and produce lipids for biofuel production, which is essential for increasing biomass production and amount of lipids that decrease the cost of biodiesel production [5]. Microalgae as a source of renewable energy have received considerable interest; however, further optimization of mass culture conditions is necessary for microalgal biofuel production to be economically viable and sustainable [6].

The ability of microalgae to transition from photoautotrophic to mixotrophic growth is a phenomenon that exists in a number of genera and species throughout the major taxonomic divisions $[7,8]$. Many algal organisms can use either autotrophic or heterotrophic metabolic processes for growth; therefore, they can photosynthesize and utilize organic materials [9]. In heterotrophy, algae grow in darkness where cells get energy completely from organic carbon in the media, while in mixotrophy, algae can obtain energy from both organic carbon and light. Such a condition is suitable for algal species that cannot grow in complete darkness but require low light or agitation [10, 11]. Growth rate and biomass production for some algae in mixo- or heterotrophic conditions can be several times higher than those in a photoautotrophic condition alone [11]. Moreover, the synthesis of metabolic products such as lipids and pigments is influenced by the quality and quantity of organic carbon. The use of organic carbon in mixotrophic culture would also reduce the need for carbon dioxide in the culture and facilitate the growth of algal species sensitive to agitation [12]. Bouarab et al. [13] reported that Micractinium pusillum grew in the presence of organic substrates, such as glucose and acetate under both mixotrophic and heterotrophic conditions. It can be concluded from the above that mixotrophism is an ideal nutritional mode for high density cultivation of microalgae for the production of biofuels and functional components. However, even though the biomass and lipid productivities are significantly higher compared with those from authotrophic growth, the cost of the organic carbon sources (usually in the form of glucose or acetate) is high when compared against all other added nutrients. To overcome this high carbon cost, a cheap resource must be found. Crude glycerol, which is derived from biodiesel production process, is capable of providing such a supply. As biodiesel production continues to increase, the market is being flooded with crude glycerol [14]. Crude glycerol prices have dropped from $\$ 0.25 / \mathrm{lb}$ in 2004 to $\$ 0.025-0.05 / \mathrm{lb}$ in $2006[15,16]$. The increase supply and low
This is an Open Access article distributed under the terms of the Creative Commons Attribution Non-Commercial License (http://creativecommons. org/ licenses/by-nc/3.0/) which permits unrestricted non-commercial use, distribution, and reproduction in any medium, provided the original work is properly cited.
Received July 15, 2014 Accepted December 27, 2014

$\uparrow$ Corresponding author

Email: hjchoi@cku.ac.kr

Tel: +82-33-649-7297 Fax: +82-33-647-7535

Copyright (C) 2015 Korean Society of Environmental Engineers 
demand for crude glycerol have pushed biodiesel producers into eagerly seeking ways to dispose this by-product. Therefore, development of sustainable processes for utilizing this organic raw material is imperative.

Recently, a process using crude glycerol as a substrate for the fermentation of the microalga Schizochytrium limacinum was developed. The oleaginous Schizochytrium limacinum can produce significant amounts of total lipids and docosahexaenoic acid, particularly when grown on a variety of carbon sources, such as glucose, glycerol or fructose $[17,18]$. The above findings suggest that biodiesel-derived crude glycerol is a potential substrate for the mixotrophic cultivation of oleaginous microalgae to utilize crude glycer$\mathrm{ol}$ and reduce the production cost of microalgal biodiesel. However, there are few reports examining the effects of crude glycerol, particularly on biomass production and algal cell components under mixotrophic conditions. In this study, the effects of various concentrations of crude glycerol on the biomass growth and oil content of Neochloris oleabundans, Botryococcus Braunii and Dunaliella sp. under mixotrophic conditions were evaluated.

\section{Materials and Methods}

\subsection{Microalgae Cultures and Medium}

The investigated microalgae isolated from KMCC (Korea Marine Microalgae Culture Center). The seed cultures of Neochloris oleabundans (N. Oleabundans), Botryococcus Braunii (B. Braunii) and Dunaliella sp. were cultivated in Jaworski's medium (JM) under light emitting diode (LED) lamps at ambient temperature. JM comprises $4.0 \mathrm{~g} \mathrm{Ca}\left(\mathrm{NO}_{3}\right)_{2} \cdot \mathrm{H}_{2} \mathrm{O}$, $2.48 \mathrm{~g} \mathrm{KH}_{2} \mathrm{PO}_{4}, 10.0$ g $\mathrm{MgSO}_{4} \cdot 7 \mathrm{H}_{2} \mathrm{O}, 3.18$ g $\mathrm{NaHCO}_{3}, 0.45$ g EDTAFeNa, 0.45 g EDTANa, $0.496 \mathrm{~g} \mathrm{H}_{3} \mathrm{BO}_{3}$, $0.278 \mathrm{~g} \mathrm{MnCl}_{2} \cdot 4 \mathrm{H}_{2} \mathrm{O}, 0.20 \mathrm{~g}\left(\mathrm{NH}_{4}\right)_{6} \mathrm{Mo}_{7} \mathrm{O}_{24} \cdot 4 \mathrm{H}_{2} \mathrm{O}, 0.008$ g cyanocobalamin, $0.008 \mathrm{~g}$ thiamine $\mathrm{HCl}, 0.008 \mathrm{~g}$ biotin, $16.0 \mathrm{~g} \mathrm{NaNO}_{3}$ and $7.2 \mathrm{~g} \mathrm{Na}_{2} \mathrm{HPO}_{4} \cdot 12 \mathrm{H}_{2} \mathrm{O}$ in $200 \mathrm{~mL}$ deionized water. The microalgae were cultured in $200 \mathrm{~mL}$ conical flask containing $100 \mathrm{~mL}$ of JM $\mathrm{pH}(7.2 \pm 0.3)$, and then $10 \mathrm{~mL} \mathrm{~N}$. Oleabundans, Botryococcus Braunii and Scenedesmus sp. were added. The cultures were maintained in a dark and light cycle of 8 and $16 \mathrm{hr}$, respectively.

\subsection{Experimental Design}

\subsubsection{Optical panel photobioreactor (OPPBR) construction and op- eration}

A schematic diagram of the OPPBR is shown in Fig. 1(a). The OPPBR was operated at a 15-L working volume and was equipped with an OP in each reactor. The initial concentrations of the inoculated microalgae were $N$. Oleabundans, $0.357 \pm 0.7 \mathrm{~g} / \mathrm{L}, B$. Braunii, $0.342 \pm 0.7 \mathrm{~g} / \mathrm{L}$ and Dunaliella sp., $0.367 \pm 0.6 \mathrm{~g} / \mathrm{L}$. The experiments were conducted at neutral $\mathrm{pH}(7.2 \pm 0.3)$ under dark and light cycles of 8 and $16 \mathrm{hr}$, respectively. The temperature was maintained at $23 \pm 1^{\circ} \mathrm{C}$ using LEDs for 20 days. The OPPBRs were aerated continuously at an aeration rate of $0.5 \mathrm{~L} / \mathrm{min} . \mathrm{CO}_{2}$ at the equivalent aeration rate of $0.02 \mathrm{vvm}$ (ca. 2\%) was used for cultivation. The OPPBR was designed such that the light source (22 LEDs), an LED panel (bar type), was placed in the OPPBR. A v-grooved optical panel (OP) was inserted underneath

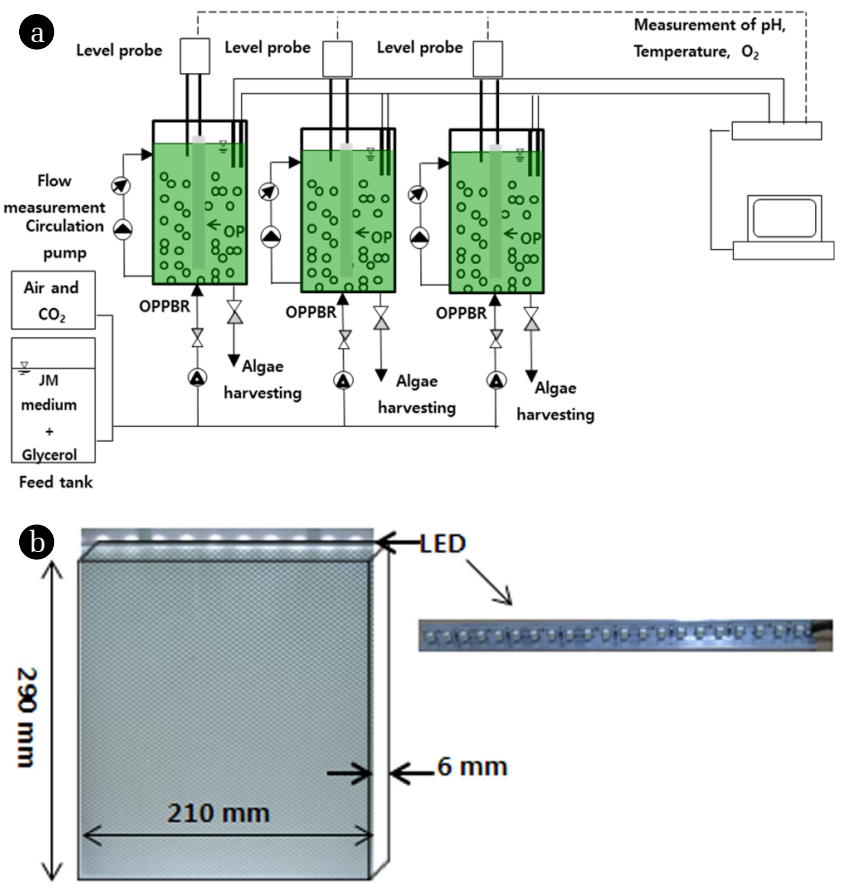

Fig. 1. (a) A schematic of OPPBR, (b) Optical panel with LEDs.

this in the photobioreactor (PBR). The thickness of the OP was $6 \mathrm{~mm}$ ( $c f$. Fig. 1(b)). The light incident was uniformly distributed across both sides of the OP in the reactor and provides greater functionality. The LED light source was used because it was efficient and provided the required wavelength light from $430 \mathrm{~nm}$ to 670 $\mathrm{nm}$, which is selective for microalgal growth. Moreover, the light intensity, which represents the amount of light used for photosynthesis, was $\sim 250 \mu \mathrm{mol}$ photons $/\left(\mathrm{m}^{2} \cdot \mathrm{s}\right)$. The mixotrophic conditions for algae cultivation were achieved with crude glycerol purchased as a byproduct of biodiesel production. The corresponding amount of crude glycerol was added to the JM growth medium to achieve to the desired mixotrophic medium.

\subsubsection{Optical panel in photobioreactor}

The characteristics of the OP are listed in Table 1. The OP exhibited $93 \%$ transmittance and $1.19 \mathrm{~g} / \mathrm{cm}^{2}$ specific gravity. The OP dimensions were $210 \mathrm{~mm}(\mathrm{~L}) \times 290 \mathrm{~mm}(\mathrm{H}) \times 6 \mathrm{~mm}(\mathrm{~W})$ as shown in Fig. 1(b) and were constructed from a transparent panel of pure PMMA (poly-methylmethacrylate). This material has good transparency and its light absorption in the visible region is negligible [19].

In this study, a v-cut OP (Fig. 1(b)) was designed. This was used to evaluate and assess the quantitative effects of the illumination area and OP arrangement on cell growth and biomass productivity. With the v-cut technology, the light was guided into the v-grooves that have $\mathrm{x}-, \mathrm{y}$ - and $\mathrm{z}$ - direction dimensions, such as enlarged horizontal and vertical grooves. The vertical v-grooves are widely spaced when they are close to the light source and narrow when distant from the light source. The enlarged horizontal v-grooves are arranged in straight lines along the 
Table 1. Characteristics of Optical Panel (OP)

\begin{tabular}{cccc}
\hline Parameters & Method & Unit & v-cut OP \\
\hline Specific gravity & ISO 1183 & - & 1.19 \\
Transmittance & ISO 13468 & $\%$ & 93 \\
Heat distortion & ISO 75 & ${ }^{\circ} \mathrm{C}$ & 94 \\
temperature & & & \\
Melt flow rate & ISO 1133 & $\mathrm{~g} / 10 \mathrm{~min}$ & 1.5 \\
Tensile strength & ISO 527 & $\mathrm{MPa}$ & 75 \\
Mold shrinkage & MRC method & $\%$ & $0.2-0.6$ \\
\hline
\end{tabular}

$\mathrm{x}$-direction from the end edge of the OP and have maximum enlarged portions located on the other edge of the OP. In addition, the v-cut is varied to provide a uniform distribution of light in the PBR.

\subsection{Analytical Methods}

2.3.1. Measurement of cell weight and specific growth rate The effect of the crude glycerol concentrations $(0,2,5$ and 10 $\mathrm{g} / \mathrm{L}$ ) added during the initial growth phase was evaluated in relation to the growth of the algae biomass and lipid accumulation. Previous study was reported that the high concentration of glycerol $(10 \%)$ showed an inhibitory effect on the growth of microalgae [15, 20]. To determine the biomass concentration, a sample of microalgae in growth medium was centrifuged for $10 \mathrm{~min}$ at $628 \mathrm{~g}$, washed with distilled water and then dried in an oven at $105^{\circ} \mathrm{C}$ for 24 hr to a constant weight. The biomass productivity $P(\mathrm{~g} /(\mathrm{L} \cdot$ day $))$ was calculated from the variation in biomass concentration $(\mathrm{g} / \mathrm{L})$ within a cultivation time (in days) according to the following equation:

$$
P=\left(X_{1}-X_{0}\right) /\left(t_{1}-t_{0}\right)
$$

The specific growth rate $\mu$ (in days) was calculated using Eq. (2)

$$
\mu=\operatorname{In}\left(X_{1} / X_{0}\right) /\left(t_{1}-t_{0}\right)
$$

where $X_{1}$ and $X_{0}$ are the biomass concentration (g/L) on days $t_{1}$ and $t_{0}$, respectively.

\subsubsection{Extraction of lipids}

The algal biomass for lipid extraction was prepared by centrifugation and drying. After oven drying, the algae were pulverized and subjected to Soxhlet extraction. All Soxhlet extractions were performed for $72 \mathrm{hr}$ using $500 \mathrm{~mL}$ solvent for $1 \mathrm{~g}$ of pulverized dry algae with a cycle time of 10-15 min. The Soxhlet extraction with hexane was selected because the Bligh and Dyer [21] extraction method is suitable for the extraction of all lipids, including triglycerides, phospholipids and other pigments [22]. The lipid content does not reflect the exact amount of triacylglycerols (TAG; consisting of a glycerol moiety with each hydroxyl group esterified to a fatty acid) because only triglycerides are used in the synthesis of biodiesel and other components are undesirable. The excess hexane was evaporated by rotary evaporation until the total volume reached 30-40 mL. The solutions were diluted to $50 \mathrm{~mL}$ and used to determine the TAG content. The amount of TAG was determined using a Fourier transform infrared (FTIR) spectrometer Spectrum RX 1 (Perkin Elmer) according to the carbonyl stretching absorption at $17401 / \mathrm{cm}$ [23]. The amount of TAG in the extract solutions was determined using a standard graph, and the amount of TAG was calculated in the dry algae $(\%, w / w)$. The experiments were performed five times, and mean values and the standard deviation was calculated.

\subsubsection{Measurement of fatty acids composition}

The fatty acid composition of the algae oil was determined using the standards EN ISO 5508 and EN ISO 5509. The analysis was performed with a Clarus 500 (Perkin Elmer) gas chromatograph. The conditions for analysis were as follows: capillary column Alltech AT-FAME (30 m - $0.25 \mathrm{~mm}-0.25 \mu \mathrm{m})$, initial oven temperature of $210^{\circ} \mathrm{C}$ held for $5 \mathrm{~min}$ then increased at $20^{\circ} \mathrm{C} / \mathrm{min}$ from $210^{\circ} \mathrm{C}$ to $230^{\circ} \mathrm{C}$ and held at $230^{\circ} \mathrm{C}$ for $12 \mathrm{~min}$. Nitrogen was used as the carrier gas. The injector temperature was $250^{\circ} \mathrm{C}$. The fatty acids were identified by comparing their retention times with the standards. The experiments were performed five times and the mean values and standard deviations were calculated.

\section{Results and Discussion}

\subsection{Effect of Glycerol Concentration on the Growth of Algal Species}

Fig. 2 shows the effect of different glycerol concentrations on the growth of $N$. Oleabundans compared to growth on JM medium. During the first five days, the microalgae grew similarly in all growth media with different amounts of glycerol. A slight difference in biomass is characteristic of a growth medium with initial concentrations of $2 \mathrm{~g} / \mathrm{L}$ and $10 \mathrm{~g} / \mathrm{L}$. The maximum biomass concentrations of $1.61,1.91$ and $1.72 \mathrm{~g} / \mathrm{L}$ were obtained in the medium containing 2, 5 and $10 \mathrm{~g} / \mathrm{L}$, respectively. By comparison, the highest biomass concentration with $5 \mathrm{~g} / \mathrm{L}$ glycerol was $39.42 \%$ higher than the concentration achieved with $N$. Oleabundans in autotrophic medium, which was $1.37 \mathrm{~g} / \mathrm{L}$. All media with glycerol yielded a higher biomass than the autotrophic condition.

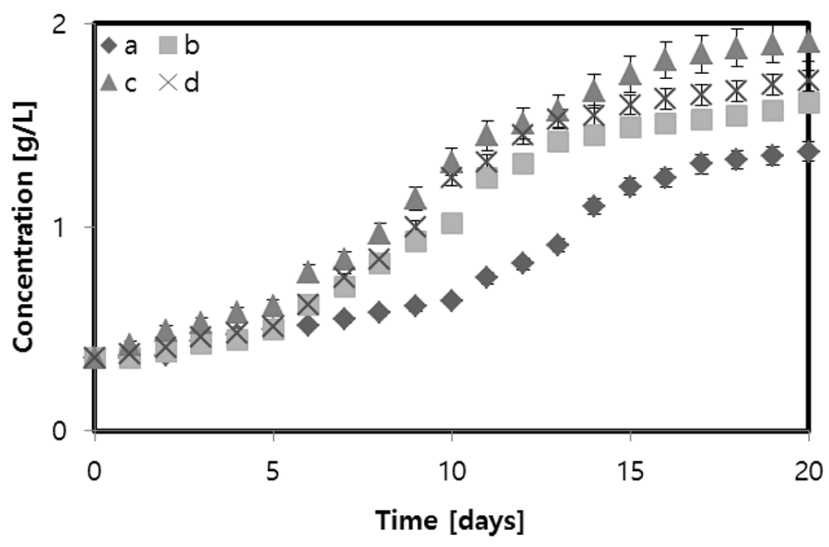

Fig. 2. Growth of Neochloris oleabundans in various glycerol concentrations (a: 0, b: 2, c: 5 and $\mathrm{d}: 10 \mathrm{~g} / \mathrm{L}$ ). 


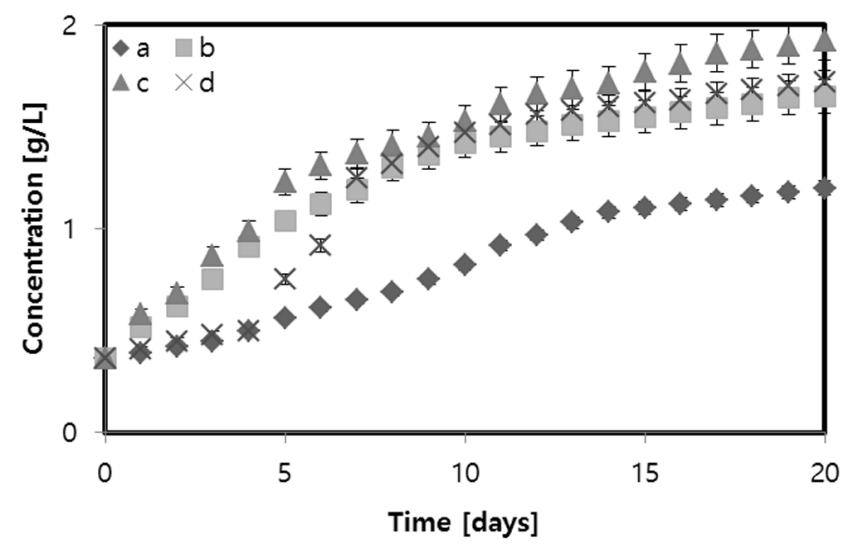

Fig. 3. Growth of Dunaliella sp. in different glycerol concentrations (a: 0, b: 2, c: 5 and d: $10 \mathrm{~g} / \mathrm{L}$ ).

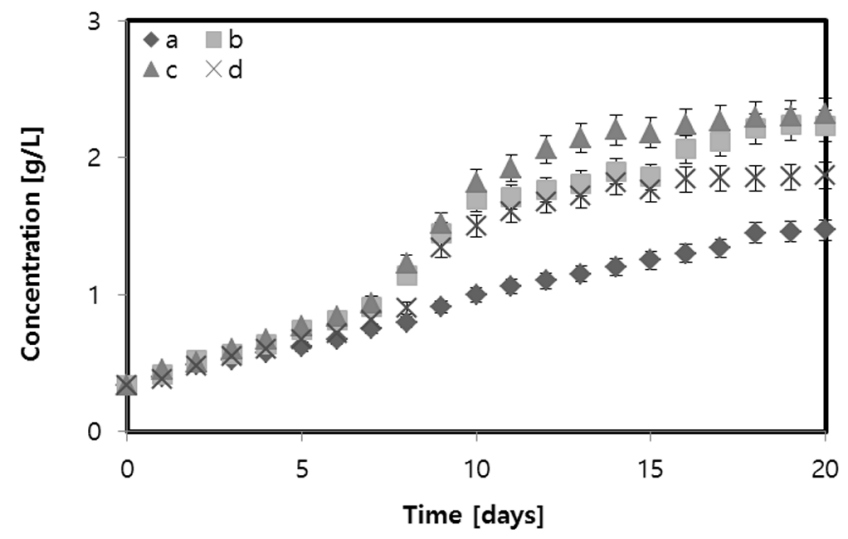

Fig. 4. Growth of Botryococcus braunii in various glycerol concentrations (a: 0, b: 2, c: 5 and d: $10 \mathrm{~g} / \mathrm{L}$ ).

The growth process was observed for Dunaliella sp. in JM medium with different glycerol concentrations (Fig. 3). During the first 4 days, the microalgae grew similarly in the autotrophic condition and $10 \mathrm{~g} / \mathrm{L}$ glycerol. Additionally, for the media with 2 $\mathrm{g} / \mathrm{L}$ and $5 \mathrm{~g} / \mathrm{L}$ glycerol, the growth was similar for 4 days. Faster growth was observed for the medium with $5 \mathrm{~g} / \mathrm{L}$ glycerol. The highest biomass concentration $(1.92 \mathrm{~g} / \mathrm{L})$ was obtained during the stationary growth phase. This concentration is $60.00 \%$ higher than the microalgae concentration in the autotrophic medium, which was $1.20 \mathrm{~g} / \mathrm{L}$. These data indicate that Dunaliella sp. grew better under mixotrophic conditions using crude glycerol compared to the autotrophic condition.

Biomass growth during all phases was characteristic of B. Braunii cultures as shown in Fig. 4. During the first 5 days, the microalgae grew similarly in all growth media with different amounts of glycerol. The biomass concentrations for $2 \mathrm{~g} / \mathrm{L}$ and $5 \mathrm{~g} / \mathrm{L}$ glycerol were similar. The highest achieved biomass concentrations $(2.23$ $\mathrm{g} / \mathrm{L}$ and $2.32 \mathrm{~g} / \mathrm{L}$ ) were similar for the same concentrations of glycerol ( $2 \mathrm{~g} / \mathrm{L}$ and $5 \mathrm{~g} / \mathrm{L}$ ) and were $51.70 \%$ and $57.82 \%$ higher than the corresponding biomass concentrations obtained without glycerol (the highest concentration was $1.47 \mathrm{~g} / \mathrm{L}$ ). Therefore, glycerol has a large impact on the growth of $B$. Braunii compared to autotrophic growth in JM medium. A slight decrease in the biomass of 1.87 g/L was obtained with $10 \mathrm{~g} / \mathrm{L}$ glycerol.

As shown in Table 2, all algae species showed maximum biomass productivity and maximum specific growth rates with glycerol concentrations ranging from 0 to $10 \mathrm{~g} / \mathrm{L}$. N. Oleabundans achieved $0.227 \mathrm{~g} /(\mathrm{L} \cdot$ day) maximum biomass productivity and 0.3421 /day maximum specific grow rate with $5 \mathrm{~g} / \mathrm{L}$ glycerol. The maximum biomass productivity $(0.231 \mathrm{~g} /(\mathrm{L} \cdot$ day $))$ and maximum specific growth rate (0.306 1/day) were achieved with $5 \mathrm{~g} / \mathrm{L}$ glycerol for Dunaliella sp. B. Braunii showed no significant differences in the highest values of the maximum biomass productivity (0.258 and $0.271 \mathrm{~g} /(\mathrm{L} \cdot$ day $))$ and maximum specific growth rate $(0.228$ and 0.301 1/day) with $2 \mathrm{~g} / \mathrm{L}$ and $5 \mathrm{~g} / \mathrm{L}$ glycerol. However, the maximum biomass productivity and maximum specific growth rate for the autotrophic condition was lower compared to the mixotrophic conditions.

There are three metabolic possibilities for the cultivation of microalgae, autotrophic, heterotrophic and mixotrophic growth. During mixotrophic growth, there are two distinctive processes, photosynthesis and aerobic respiration. The former is influenced by light intensity, and the latter is related to the organic substrate (glycerol or glucose) concentration [10, 20]. The highest biomass concentration of the three investigated microalgae species under mixotrophic conditions was achieved with $5 \mathrm{~g} / \mathrm{L}$ crude glycerol in the JM medium. Similar concentrations of microalgae biomass were obtained by other scientists who investigated the mixotrophic growth of microalgae with glycerol. Andruleviciute et al. [24] reported 1.92, 2.15, 1.87 and $2.25 \mathrm{~g} / \mathrm{L}$ as the highest biomass concentrations for Chlorella sp., Scenedesmus sp., Haematococcus sp. and Nannochloris sp., respectively, in growth medium containing 5 g/L glycerol. Cerón Garcia et al. [25] investigated the cultivation of Chlorella vulgaris in growth medium containing 1, 5 and 10 g/L glycerol. In the growth medium with 5 g/L glycerol, the concentration of microalgae biomass increased to $2.13 \mathrm{~g} / \mathrm{L}$ (in our study $1.91 \mathrm{~g} / \mathrm{L})$. Liang et al. [26] concluded that only the highest amount (10 g/L) of glycerol had an inhibitory effect and that for lower concentrations of glycerol, the biomass concentration was increased compared to the autotrophic conditions (from $0.25 \mathrm{~g} / \mathrm{L}$

Table 2. The Maximum Biomass Productivity $P_{\max }$ and Maximum Specific Growth Rate $\mu_{\max }$ of Algae Species

\begin{tabular}{ccccccc}
\hline $\begin{array}{c}\text { Glycerol } \\
\text { concentration }\end{array}$ & \multicolumn{2}{c}{ Neochloris oleabundans } & \multicolumn{2}{c}{ Dunaliella sp. } & \multicolumn{2}{c}{ Botryococcus braunii } \\
\cline { 2 - 7 } & $\boldsymbol{P}_{\max }$ & $\boldsymbol{\mu}_{\max }$ & $\boldsymbol{P}_{\max }$ & $\boldsymbol{\mu}_{\max }$ & $\boldsymbol{P}_{\max }$ & $\boldsymbol{\mu}_{\max }$ \\
\hline 0 & $0.089 \pm 0.002$ & $0.158 \pm 0.013$ & $0.078 \pm 0.002$ & $0.127 \pm 0.004$ & $0.051 \pm 0.005$ & $0.128 \pm 0.004$ \\
5 & $0.148 \pm 0.004$ & $0.188 \pm 0.011$ & $0.191 \pm 0.023$ & $0.217 \pm 0.025$ & $0.258 \pm 0.027$ & $0.228 \pm 0.024$ \\
10 & $0.227 \pm 0.013$ & $0.342 \pm 0.007$ & $0.231 \pm 0.019$ & $0.306 \pm 0.017$ & $0.271 \pm 0.002$ & $0.301 \pm 0.016$ \\
\hline
\end{tabular}

Units: Glycerol concentration $(\mathrm{g} / \mathrm{L}), P_{\max }(\mathrm{g} /(\mathrm{L} \cdot$ day $)), \mu_{\max }(1 /$ day $)$. 
under autotrophic conditions to $0.722 \mathrm{~g} / \mathrm{L}$ under mixotrophic conditions with $1 \mathrm{~g} / \mathrm{L}$ glycerol).

In the present study, the glycerol concentration in mixotrophic systems influences the biomass concentration and growth rate of N. Oleabundans, B. Braunii and Dunaliella sp. The highest concentration was obtained $39.42 \%, 60.00 \%$ and $57.82 \%$ for $N$. Oleabundans, Dunaliella sp. and B. Braunii in the mixotrophic conditions with $5 \mathrm{~g} / \mathrm{L}$ glycerol, respectively. For increased biomass concentration, Dunaliella sp. is the best algae species for growth in mixotrophic medium enriched with glycerol. The results of this study suggest that the investigated algae species may be excellent biofuel producers because organic materials stimulate the growth rate of these strains.

\subsection{Total Fatty Acids in Algae Species}

The total TAG content using the different glycerol concentrations are represented in Table 3. The highest TAG content was $15.91 \%$, $16.24 \%$ and $16.41 \%$ for $N$. Oleabundans, Dunaliella sp. and $B$. Braunii, respectively, with $5 \mathrm{~g} / \mathrm{L}$ glycerol. The $5 \mathrm{~g} / \mathrm{L}$ glycerol medium was determined $12.20 \%, 13.11 \%$ and $9.30 \%$ for N. Oleabundans, Dunaliella sp. and B. Braunii, respectively. All microalgal species under mixotrophic condition had 2-13\% higher lipid content than the autotrophic condition. The 2 and $10 \mathrm{~g} / \mathrm{L}$ glycerol media yielded similar TAG contents for N. Oleabundans and Dunaliella sp. However, for B. Braunii,, 2 g/L glycerol was approximately $6 \%$ higher than the $10 \mathrm{~g} / \mathrm{L}$ glycerol. The highest lipid content was $16.41 \%$ for Botryococcus braunii with $5 \mathrm{~g} / \mathrm{L}$ glycerol.

Compared to the autotrophic conditions, using glycerol for the cultivation of microalgae increased the lipid content of all algae species. The TAG content in the microalgae cells increases with $5 \mathrm{~g} / \mathrm{L}$ glycerol for the algae species. However, $10 \mathrm{~g} / \mathrm{L}$ glycerol decreased the lipid oil content for the algae species. Liang et al. [27] observed an increase in lipid content with increasing concentrations of glycerol. The lipid content increased from $22 \%$ with $1 \mathrm{~g} / \mathrm{L}$ glycerol to $32 \%$ with $2 \mathrm{~g} / \mathrm{L}$ glycerol. However, the highest amount $(10 \mathrm{~g} / \mathrm{L})$ of glycerol had an inhibitory effect for growth of algae and TAG content. Too many glycerols in the media were causing death of microalgae.

The sensitivity analysis showed that the initial glycerol concentration was the most significant factor for algal growth and lipid production [28]. Chen and Walker [29] reported that in batch mode, the biomass and lipid concentration in Chlorella protothecoides cultivated in crude glycerol medium were 23.5 and 14.6 g/L, respectively, during a 6 day cultivation. This study demonstrated the feasibility of crude biodiesel glycerol as an alternative carbon substrate to glucose for microalgae cultivation, and a cost reduction of the carbon substrate feed for microalgal lipid production is expected. Similar results were observed in the current study. In mixotrophic cultures, the lipid contents were $4.50 \%$ to $12.20 \%, 3.19 \%$ to $13.11 \%$ and $2.22 \%$ to $9.30 \%$ for N. Oleabundans, Dunaliella sp. and B. Braunii, respectively, which were higher than the autotrophic culture.

The lipid content and effectiveness of microalgae growth for biodiesel production are important. Improved accumulation of oil but slower growth of microalgae may result in lower oil yields compared to faster growing microalgae with less oil accumulation. The results of this study showed that B. Braunii grown with 5 $\mathrm{g} / \mathrm{L}$ glycerol accumulated the highest concentration of TAG and that growth in this medium was also higher in other glycerol containing medium. B. Braunii grown in $2 \mathrm{~g} / \mathrm{L}$ glycerol had a lower TAG content compared to N. Oleabundans and Dunaliella sp. grown in $5 \mathrm{~g} / \mathrm{L}$ glycerol, which had low biomass concentrations. N. Oleabundans, Dunaliella sp. grown in $5 \mathrm{~g} / \mathrm{L}$ glycerol accumulated higher contents of TAG than in other glycerol concentrations. Therefore, to obtain high TAG content, the recommended mixotrophic condition for the microalgae species is $5 \mathrm{~g} / \mathrm{L}$ glycerol.

\subsection{Composition of Total Fatty Acids}

The fatty acid profiles of the algae oil are shown in Table 4. For this experiment, we selected the samples with the highest oil contents, N. Oleabundans, Dunaliella sp. and B. Braunii using $5 \mathrm{~g} / \mathrm{L}$ glycerol. For comparison, the profiles of the fatty acids of the autotrophic cultures and rapeseed oil, commonly used for biodiesel fuel production, are also provided. The contents of the saturated fatty acids of $N$. Oleabundans, Dunaliella sp. and B. Braunii were $34.94 \%, 20.23 \%$ and $21.39 \%$, respectively, and the amount of unsaturated fatty acids was $65.06 \%, 79.77 \%$ and $78.61 \%$, respectively, under mixotrophic conditions. The largest impact of glycerol was on the fatty acid profiles of N. Oleabundans. The saturated fatty acid content changed from $16.91 \%$ to $34.94 \%$ for the autotrophic condition and $5 \mathrm{~g} / \mathrm{L}$ glycerol, respectively.

The other species did not significantly change. Dunaliella sp. and B. Braunii had changes in the saturated fatty acids content from $13.27 \%$ to $20.23 \%$ and from $16.28 \%$ to $21.39 \%$, respectively. The unsaturated fatty acid content was 65.06\%, 79.77\% and 78.61\% for N. Oleabundans, Dunaliella sp. and B. Braunii, respectively.

The most common source for the synthesis of biofuel is rapeseed oil. The quality of biofuels produced from rapeseed oil is specified by the requirements of the European Standard EN 14214. The quality parameters of biodiesel are influenced by the fatty acid composition of the oil [24]. The results of this study showed that

Table 3. Total TAG Content in the Dry Mass of Algae Species

\begin{tabular}{cccc}
\hline \multirow{2}{*}{ Glycerol concentration $[\mathrm{g} / \mathrm{L}]$} & \multicolumn{2}{c}{ Total TAG content in the dry biomass of algae* $(\%)$} \\
\cline { 2 - 4 } & Neochloris oleabundans & Dunaliella sp. & Botryococcus Braunii \\
\hline 0 & $3.71 \pm 0.51$ & $3.13 \pm 0.42$ & $7.11 \pm 1.21$ \\
5 & $8.73 \pm 1.43$ & $6.74 \pm 0.76$ & $15.02 \pm 1.67$ \\
10 & $15.91 \pm 1.30$ & $16.24 \pm 1.40$ & $16.41 \pm 1.53$ \\
\hline
\end{tabular}

* The data from 20-day cell growth was used for the determination.

Tag: Triacylglycerols. 
Table 4. Composition of Total Fatty Acid Profiles of the Algae Oil

\begin{tabular}{|c|c|c|c|c|c|c|c|c|}
\hline \multirow{3}{*}{$\begin{array}{c}\text { Fatty acids } \\
\text { Glycerol concentration }[\mathrm{g} / \mathrm{L}]\end{array}$} & \multicolumn{6}{|c|}{ Composition (\%) of total fatty acids } & \multirow{3}{*}{ Rapeseed } & \multirow{3}{*}{ Corn } \\
\hline & \multirow{2}{*}{$\begin{array}{c}\text { Neochloris } \\
0\end{array}$} & \multirow{2}{*}{$\begin{array}{c}\text { oleabundans } \\
5\end{array}$} & \multicolumn{2}{|c|}{ Dunaliella sp. } & \multicolumn{2}{|c|}{ Botryococcus braunii } & & \\
\hline & & & 0 & 5 & 0 & 5 & & \\
\hline Saturated & $16.91 \pm 0.51$ & $34.94 \pm 0.49$ & $13.27 \pm 0.34$ & $20.23 \pm 0.38$ & $16.78 \pm 0.27$ & $21.39 \pm 0.42$ & 5.40 & 8.3 \\
\hline C14:0 mystiric & $0.31 \pm 0.02$ & $0.31 \pm 0.03$ & $\mathrm{ND}$ & $0.58 \pm 0.04$ & $0.23 \pm 0.02$ & ND & - & - \\
\hline C16:0 palmitic & $11.09 \pm 0.84$ & $15.54 \pm 0.67$ & $7.62 \pm 0.48$ & $15.04 \pm 0.75$ & $7.78 \pm 0.54$ & $13.23 \pm 0.38$ & 3.22 & 6.5 \\
\hline C17:0 margarin & $0.47 \pm 0.04$ & $1.71 \pm 0.11$ & $0.93 \pm 0.07$ & $0.48 \pm 0.03$ & $1.55 \pm 0.14$ & $1.45 \pm 0.08$ & - & 0.2 \\
\hline C18:0 stearic & $4.11 \pm 0.12$ & $5.76 \pm 0.07$ & $2.81 \pm 0.09$ & $2.85 \pm 0.06$ & $3.99 \pm 0.12$ & $5.84 \pm 0.13$ & 2.18 & 1.4 \\
\hline C20:0 arachidic & $0.57 \pm 0.03$ & $4.13 \pm 0.24$ & $0.73 \pm 0.02$ & $0.47 \pm 0.04$ & $1.37 \pm 0.03$ & $0.77 \pm 0.02$ & - & 0.1 \\
\hline C22:0 behenic & $0.24 \pm 0.02$ & $5.27 \pm 0.24$ & $1.09 \pm 0.12$ & $0.71 \pm 0.07$ & $1.81 \pm 0.07$ & $0.04 \pm 0.01$ & - & - \\
\hline C24:0 lignoceric & $0.13 \pm 0.02$ & $2.22 \pm 0.08$ & $0.09 \pm 0.01$ & $0.1 \pm 0.04$ & $0.05 \pm 0.03$ & $0.06 \pm 0.02$ & - & 0.1 \\
\hline Unsaturated & $83.09 \pm 2.31$ & $65.06 \pm 2.48$ & $86.73 \pm 3.58$ & $79.77 \pm 3.46$ & $83.22 \pm 2.61$ & $78.61 \pm 1.56$ & 94.60 & 91.7 \\
\hline C16:1 palmitoleic & $2.28 \pm 0.27$ & $2.10 \pm 0.38$ & $2.07 \pm 0.07$ & $2.10 \pm 0.07$ & $1.66 \pm 0.03$ & $2.49 \pm 0.04$ & - & 0.6 \\
\hline C18:1 oleic & $53.01 \pm 1.14$ & $34.54 \pm 2.06$ & $62.27 \pm 2.51$ & $47.05 \pm 1.67$ & $50.43 \pm 1.21$ & $48.36 \pm 1.65$ & 16.92 & 65.6 \\
\hline C18:2 linoleic & $20.99 \pm 1.35$ & $9.42 \pm 1.31$ & $12.72 \pm 2.15$ & $17.65 \pm 1.95$ & $14.65 \pm 2.11$ & $19.73 \pm 1.23$ & 66.32 & 25.2 \\
\hline C18:3 linolenic & $6.04 \pm 1.11$ & $7.42 \pm 1.24$ & $5.44 \pm 0.48$ & $11.12 \pm 0.87$ & $10.94 \pm 1.38$ & $7.03 \pm 1.41$ & 11.14 & 0.1 \\
\hline C20:1 gadoleic & $0.51 \pm 0.09$ & $2.90 \pm 0.04$ & $2.12 \pm 0.03$ & $0.82 \pm 0.12$ & $4.59 \pm 0.24$ & $0.75 \pm 0.07$ & - & 0.1 \\
\hline C22:1 erucic & $0.24 \pm 0.03$ & $5.63 \pm 0.12$ & $0.62 \pm 0.07$ & $0.38 \pm 0.07$ & $0.83 \pm 0.13$ & $0.20 \pm 0.05$ & 0.22 & 0.1 \\
\hline C24:1 nervonic & $0.02 \pm 0.01$ & $3.05 \pm 0.21$ & $1.49 \pm 0.56$ & $0.65 \pm 0.04$ & $0.12 \pm 0.07$ & $0.05 \pm 0.01$ & - & - \\
\hline
\end{tabular}

ND: not detected.

The data from 20-day cell growth in medium.

the content of the saturated fatty acids in algal oil is higher than in rapeseed oil (5.40\%) and that the content of the unsaturated fatty acids is lower (94.60\% in rapeseed oil). A small amount of saturated fatty acids (34.94\%) and a large amount of unsaturated fatty acids (65.06\%) was characteristic for N. Oleabundans oil, while the other species had greater amounts of unsaturated fatty acids compared with saturated fatty acids.

A high proportion of polyunsaturated fatty acids for biodiesel are not wanted because they adversely impact the stability of the biodiesel [22]. For user acceptance, microalgae biodiesel will need to comply with existing standards. Microalgae oils differ from most vegetable oils in being quite rich in polyunsaturated fatty acids with four or more double bonds. For example, eicosapentaenoic acid (EPA, C20:5n-3; five double bonds) and docosahexaenoic acid (DHA, C22:6n-3; six double bonds) occur commonly in algal oils [30]. Fatty acids and fatty acid methyl ester (FAME) with 4 and more double bonds are susceptible to oxidation during storage and this reduces their acceptability for use in biodiesel. Some vegetable oils (Soybean and sunflower etc.) also face this problem. Although these fatty acids have much higher oxidative stability compared with DHA and EPA, the European Standard EN 14214 limits linolenic acid methyl ester content in biodiesel for vehicle use to $12 \%$ (mol). No such limitation exists for biodiesel intended for use as heating oil, but acceptable biodiesel must meet other criteria relating to the extent of total unsaturation of the oil $[14,24,30]$. Total unsaturation of oil is indicated by its iodine value. Standards EN 14214 and EN 14213 require the iodine value of biodiesel to not exceed 120 and 130 g iodine/100 g biodiesel, respectively. Furthermore, both the European biodiesel standards limit the contents of FAME with four and more double bonds, to a maximum of $1 \%$ mol. In view of the composition of many microalgae oils, most of them are unlikely to comply with the European biodiesel standards, but this need not be a significant limitation [14-16]. The extent of unsaturation of microalgae oil and its content of fatty acids with more than 4 double bonds can be reduced easily by partial catalytic hydrogenation of the oil [31]. Compared to rapeseed oil (59.1-66.3) and corn oil (22.3-25.2), the algal oil (9.42-20.99) is not as rich in polyunsaturated fatty acids. Rapeseed biodiesel presented a cetane number near to palm biodiesel. However higholeic sunflower and corn biodiesels, those which were richer in unsaturated ester of linoleic acid (C18:2), presents a cetane number in medium range [30].

Furthermore, the content of linolenic acid in the algae species corresponds to the requirements of the Standards EN 14214, which states that the content of linolenic acid methyl ester in biodiesel fuel should not exceed $12 \%$. Therefore, the biodiesel fuel produced from algae oil will likely meet the requirements for the linolenic acid methyl ester content.

\section{Conclusions}

The growth of the algae strains N. Oleabundans, Dunaliella sp. and $B$. Braunii under mixotrophic conditions in the presence of different concentrations of crude glycerol was investigated with the objective of increasing the biomass growth and algae oil content. The highest biomass concentration was obtained in medium containing $5 \mathrm{~g} / \mathrm{L}$ glycerol for $N$. Oleabundans, Dunaliella sp. and $B$. Braunii and was $39.42 \%, 60.00 \%$ and $57.82 \%$ higher, respectively, than for the autotrophic growth of these species. The maximum biomass productivity with $5 \mathrm{~g} / \mathrm{L}$ glycerol was $0.227,0.231$ and 
$0.271 \mathrm{~g} /(\mathrm{L} \cdot$ day $)$ and maximum specific growth rate $0.342,0.306$ and 0.301 1/day for N. Oleabundans, Dunaliella sp. and B. Braunii, respectively. The content of TAG under mixotrophic conditions was higher than under the autotrophic conditions. In particular, the TAG contents for $5 \mathrm{~g} / \mathrm{L}$ glycerol medium were $12.20 \%, 13.11 \%$ and $9.30 \%$ higher for the respective autotrophic conditions. The content of the saturated fatty acids for N. Oleabundans, Dunaliella sp. and B. Braunii was $34.94 \%, 20.23 \%$ and $21.39 \%$, and the unsaturated fatty acids was $65.06 \%, 79.77 \%$ and $78.61 \%$ under mixotrophic conditions, respectively. Based on the results of this experiment, Dunaliella sp. in the mixotrophic condition was shown to provide an effective for lipid content. However, the all investigated algal strains grown on glycerol produced higher biomass concentrations and lipid contents compared to the autotrophic growth. The fatty acid content of the oils from these species suggests their potential use as biodiesel feedstock.

\section{Acknowledgments}

This study was supported by the Basic Science Research Program through the National Research Foundation of Korea (NRF) funded by the Ministry of Education, Science and Technology (2013006899).

\section{References}

1. Pulz O, Grass W. Valuable products from biotechnology of microalgae. Appl. Microbiol. Biotechnol. 2004;65:635-648.

2. Borowitzka MA, Moheimani NR. Sustainable biofuels from algae. Mitig. Adapt. Strateg. Glob. Chang. 2013;18:13-25.

3. Spolaore P, Joannis-Cassan C, Duran E, Isambert A. Commercial applications of microalgae. J. Biosci. Bioeng. 2006;101:87-96.

4. Rudolfi L, Chini Zittelli G, Bassin N, et al. Microalgae for oil: strain selection, induction of lipid synthesis and outdoor mass cultivation in a low-cost photobioreactor. Biotechnol. Bioeng. 2009;102:100-112.

5. Xu H, Miao X, Wu Q. High quality biodiesel production from a microalga Chlorella protothecoides by heterotrophic growth in fermenters. J. Biotechnol. 2006;126:499-507.

6. Pittman JK, Dean AP, Osundeko O. The potential of sustainable algal biofuel production using wastewater resources. Bioresour. Technol. 2011;102:17-25.

7. Chen GQ, Chen F. Growing phototrophic cells without light. Biotechnol. Lett. 2006;28:607-616.

8. Qiao H, Wang G, Zhang X. Isolation and characterization of Chlorella sorokiniana GXNN01(Chlorophyta) with the properties of heterotrophic and microaerobic growth. J. Phycol. 2009;45:1153-1162.

9. Yang C, Hua Q, Shimizu K. Energetics and carbon metabolism during growth of microalgal cells under photoautotrophic, mixotrophic and cyclic light-autotrophic/dark-heterotrophic conditions. Biochem. Eng. J. 2000;6:87-102.

10. Zhang H, Wang W, Li Y, Yang W, Shen G. Mixotrophic cultivation of Botryococcus braunii. Biomass Bioenergy. 2011;35: 1710-1715.

11. Alkhamis Y, Qin JG. Cultivation of isochrysis galbana in photo- trophic, heterotrophic, and mixotrophic conditions. BioMed Res. Int. 2013;2013:983465.

12. Chojnacka K, Noworyta A. Evaluation of Spirulina sp. growth in photoautotrophic, heterotrophic and mixotrophic cultures. Enzyme Microb. Technol. 2004;34:461-465.

13. Bouarab L, Dauta A, Loudiki M. Heterotrophic and mixotrophic growth of Micractinium pusillum Fresenius in the presence of acetate and glucose: effect of light and acetate gradient concentration. Water Res. 2004;38:2706-2712.

14. Thompson JC, He BB. Characterization of crude glycerol from biodiesel production from multiple feedstocks. Appl. Eng. Agric. 2006;22:261-265.

15. Johnson DT, Taconi KA. The glycerol glut: Options for the value-added conversion of crude glycerol resulting from biodiesel production. Environ. Prog. 2007;26:338-348.

16. Yang F, Hanna MA, Sun R. Value-added uses for crude glycerol-a byproduct of biodiesel production. Biotechnol. Biofuels. 2002;5:1-10.

17. Chi Z, Pyle D, Wen Z, Frear C, Chen S. A laboratory study of producing docosahexaenoic acid from biodiesel-water glycerol by microalgal fermentation. Process Biochem. 2007;42: 1537-1545.

18. Pyle DJ, Garcia RA, Wen Z. Producitng docosahexaenoic acid (DHA)-rich algae from biodiesel-derived crude glycerol: effects of impurities on DHA production and algal biomass composition. J. Agric. Food Chem. 2008;56:3933-3939.

19. Choi HJ, Lee JM, Lee SM. A novel optical panel photobioreactor for cultivation of microalgae. Water Sci. Technol. 2013;67:25432548.

20. Mitra D, van Leenwen J, Lamsal B. Heterotrophic/mixotrophic cultivation of oleaginous Chlorella vulgaris on industrial co-products. Algal Res. 2012;1:40-48.

21. Bligh EG, Dyer WJ. A rapid method of total lipid extraction and purification. Can. J. Biochem. Physiol. 1959;37:911-917.

22. Sobczuk TM, Chisti Y. Potential fuel oils from the microalga Choricystis minor. J. Chem. Technol. Biotechnol. 2010;85: 100-108.

23. Stehfest K, Toepel J, Wilhelm C. The application of micro-FTIR spectroscopy to analyze nutrient stress-related changes in biomass composition of phytoplankton algae. Plant Physiol. Biochem. 2005;43:717-726.

24. Andruleviciute V, Makareviciene V, Skorupskaite V, Gumbyte M. Biomass and oil content of Chlorella sp., Haematococcus sp., Nannochloris sp. and Scenedesmus sp. under mixotrophic growth conditions in the presence of technical glycerol. J. Appl. Phycol. 2014;26:83-90.

25. Cerón García MC, Fernández Sevilla JM, Acién Fernández FG, Molina Grima E, García Camacho F. Mixotrophic growth of Phaeodactrylum tricornutum on glycerol: growth rate and fatty acid profile. J. Appl. Phycol. 2000;12:239-248.

26. Liang Y, Sarkany N, Cui Y. Biomass and lipid productivities of Chlorella vulgaris under autotrophic, heterotrophic and mixotrophic growth conditions. Biotechnol. Lett. 2009;31:10431049.

27. Liang Y, Sarkany N, Cui Y, Blackburn JM. Batch stage study of lipid production from crude glycerol derived from yellow grease or animal fats through microalgal fermentation. 
Bioresour. Technol. 2010;101:6745-6750.

28. Perez-Garcia O, de-Bashan LE, Hernandez JP, Bashan Y. Efficiency of growth and nutrient uptake from wastewater by heterotrophic, autotrophic, and mixotrophic cultivation of Chlorella vulgaris immobilized with Azospirillum brasilense. J. Phycol. 2010;46:800-812.

29. Chen YH, Walker TH. Biomass and lipid production of heterotrophic microalgae Chlorella protothecoides by using biodiesel-derived crude glycerol. Biotechnol. Lett. 2011;33:1973-
1983.

30. Ramos MJ, Fernández CM, Casas A, Rodríguez L, Pérez A. Influence of fatty acid composition of raw materials on biodiesel properties. Bioresour. Technol. 2009;100:261-268.

31. Kong WB, Yang H, Cao YT, Song H, Hua SF, Xia CG. Effects of glycerol and glucose on the enhancement of biomass, lipid and soluble carbohydrate production by Chlorella vulgaris in mixotrophic cultures. Food Technol. Biotechnol. 2013;51:62-69. 